\title{
Development and Validation of Critical Thinking Disposition Test in Biology
}

\section{Jayanti Syahfitri}

Lecturer in Muhammadiyah University of Bengkulu, Student in Universitas Pendidikan Indonesia, Indonesia, jayanti_syahfitri@student.upi.edu

\section{Harry Firman}

Dr., Universitas Pendidikan Indonesia, Indonesia, harry.firman@hotmail.com

\section{Sri Redjeki}

Prof. Dr., Universitas Pendidikan Indonesia, Indonesia, sri.redjeki.n@gmail.com

\section{Siti Sriyati}

Dr., Universitas Pendidikan Indonesia, Indonesia, sriyati@upi.edu

The purpose of this study was to develop the Critical Thinking Disposition Test in Biology as an alternative instrument in looking at the extent of one's disposition to critical thinking, especially in Biology University. Critical Thinking Disposition Tests in Biology are tests in the form of multiple choice based on biological cases. This research was applied at the University in Bengkulu which involved six experts as reviewers and 320 students as respondents, namely with the level of study: year 1 , year 2, year 3, and year 4. This research refers to the design of development and validation. Data collection techniques used were content validation formats and questionnaire. The results of expert validation were analyzed by the Content Validity Ratio (CVR) method, while the results of the construct validation were analyzed through Confirmatory Factor Analysis (CFA). The results show that the Critical Thinking Disposition Test in Biology has good content validation and construct validation.

Keywords: critical thinking disposition test, biology, CVR, CFA, Biology, test

\section{INTRODUCTION}

Instruments play a very important role in determining the quality of a study because the validity or validity of the data obtained is determined by the quality or validity of the instrument used, in addition to the data collection procedures taken. Instruments have a very important role in learning activities especially to measure a particular variable. In addition, Hamdi et al., (2018) reveal that measurement is a necessary process to

Citation: Syahfitri, J., Firman, H., Redjeki, S., \& Srivati, S. (2019). Development and Validation of Critical Thinking Disposition Test in Biology. International Journal of Instruction, 12(4), 381-392. https://doi.org/10.29333/iji.2019.12425a 
improve the quality of education. A positive change of quality is always shown by a quality of output which can also be seen through the measurement. As expressed by Ghuptal et al. (2012), the first step of the effort towards education development is to have a valid and reliable instrument study, where an instrument both test and non-test must have proof of validity and reliability, the results can be compared, and economical. Facione et al., (2000) explain that the process of developing an assessment tool in education that is good in any form starts with a construct, or the idea of the variable to be measured. The validity of the instrument construct depends on how well the idea has been articulated and how well the tool captures the idea. Other than that, the basic idea behind the design of educational assessment tools is expected to be representative. Thus, the tasks, items, questions, used in the development of the construct are representative of the learning that is being sought to be measured. Furthermore Mardapi (2008) explained that there are five important sources of evidence of validity, namely evidence based on test content, evidence-based on the response process, evidence based on internal structure, evidence-based on relationships with other variables, and evidence based on the consequences of testing.

Research shows that even though people have critical thinking skills, individuals without thinking dispositions are defective in using their thinking abilities (Sendag, et al., 2015). A person's disposition to critical thinking is a necessary prerequisite for critical thinking. This is an important factor and greatly influences critical thinking skills. Although dispositions are not skills, it remains to be determined whether a stronger tendency towards cognitive maturity predicts greater skills in making mature judgments. Therefore, cultivation of dispositions is very important to ensure the use of critical thinking skills outside instructional settings. Its use, of course, requires a measure of maturity, and personal development (Yuksel \& Alci, 2012). Furthermore, Iskifoglu (2014) revealed that assess the dispositional dimension of critical thinking is more important than judging dimension of cognitive abilities. Referring to Facione's theory (1995) critical thinking disposition covering truth-seeking, open-mind, analyticity, systematicity, self-confidence, inquisitiveness and maturity.

Many studies related to critical thinking dispositions have been conducted, the majority of which use measurement instruments with a psychological scale. The test is considered to be more able to measure mastery of concepts and processes of critical thinking objectively compared to measurements through the inventory scale. Moreover, the measurement of psychological scale such as inventory is still general, not specific and not bound to the subject of science or contextual, for example in certain subjects. In addition, measurement through a psychological scale is considered vulnerable to the deception of the response. This is supported by Widhiarso's statement (2011) stating that measurements using an inventory scale have limitations that can be intentionally manipulated and the accuracy of the resulting scores is still doubtful (usually respondents have certain motives). In addition, considering the curriculum demands in universities that require students to be able to think critically as a form of preparation for the 21st century, the instrument of critical thinking disposition needs to be inserted in the cognitive domain to help realize the curriculum's demands. Therefore, of course the 
development of assessment instruments for critical thinking dispositions in the context of certain material (biology) needs to be carried out in the form of tests.

\section{METHOD \\ Participants}

This research has been conducted at one of the Universities in Bengkulu in August 2017 until November 2017 with a total number of respondents namely 320 students. Respondents in this research were biology education students in the 2017/2018 Academic Year. Respondents were taken from each the level of study, namely year 1 (66 students), year 2 (79 students), year 3 (95 students) and year 4 (80 students).

\section{Design Research}

This research applied Development and Validation design that refer to Graham (2012) research. This design is a combination of qualitative and quantitative research. In this design an analysis of Content Validity Ratio (CVR) and Confirmatory Factor Analysis (CFA) was carried out to see the construct validity of the Critical Thinking Disposition Test in Biology. The Development and Validation research design, which consisted of four stages, namely: 1) conceptualization, 2) development of test, 3) trial of test, and 4) testing. As for the detailed procedures that refer to the stages of development and validation design, namely:

\section{Conceptualization}

The first step is understanding to a concept of biology and critical thinking disposition. This conceptualization step is intended to obtain a concept that can serve as the basis for the development of the test in the next step. At the step of developing or compiling the Critical Thinking Disposition Test in Biology a clear concept is obtained and is expected to actually produce items that represent each construct.This is in line with statement Sumintono and Widhiarso (2013) that in the process of preparing a measuring instrument. The first step taken before writing the item is to explore the theory of the construct to be measured (understanding and aspects). Biology concepts in this research include ecology, structure and function, biotechnology, and evolution. While, critical thinking disposition consists of seven indicators referring Facione Theory, they are Truth-Seeking, Open-Mind, Analyticity, Systematicity, Self-Confidence, Inquisitiveness, and Maturity.

\section{Develop}

The test developed in this study is the Critical Thinking Disposition Test in Biology with a multiple-choice type based on biological cases. There were several steps carried out at this stage, namely:

2.1. Determine the biological material and keywords of each critical thinking disposition. There are four groups of biological material taken in this study, namely: the diversity of living things and ecology, structure and function in living things, biotechnology, and genetics and evolution. The keywords of each indicator of critical thinking disposition become a reference in making question items that are associated with biological cases. 
2.2. Compile the items in the draft of the Critical Thinking Disposition Test in Biology which is made of 22 clusters of questions presented in the form of cases relating to biological content. Each question cluster consists of seven questions that refer to the critical thinking disposition indicator so that the total number of items developed is 154 questions. As for the example of the constructed item that was developed, namely:

\section{Example of item constructs}

Item constructs developed based on seven indicators of the critical thinking disposition which is related to biological content so that the item is presented in the form of a case. The sample item of the Critical Thinking Disposition Test in Biology is described in Figure 1.

"The picture below is one of the natural selection events that is seen in the number of bright winged moths that were more numerous than dark winged moths. This happens because the mossy tree that was originally light-colored will protect the bright-winged moth, so this can cause dark-winged moths to be easily eaten by predators. As time went on the trees became covered with dark-colored lichens caused by industrial waste in the UK and these conditions became more adaptive to dark-winged moths, so that eventually a change in the number of moths resulted in the development of darkwinged moths rising sharply and bright wings drastically reduced"

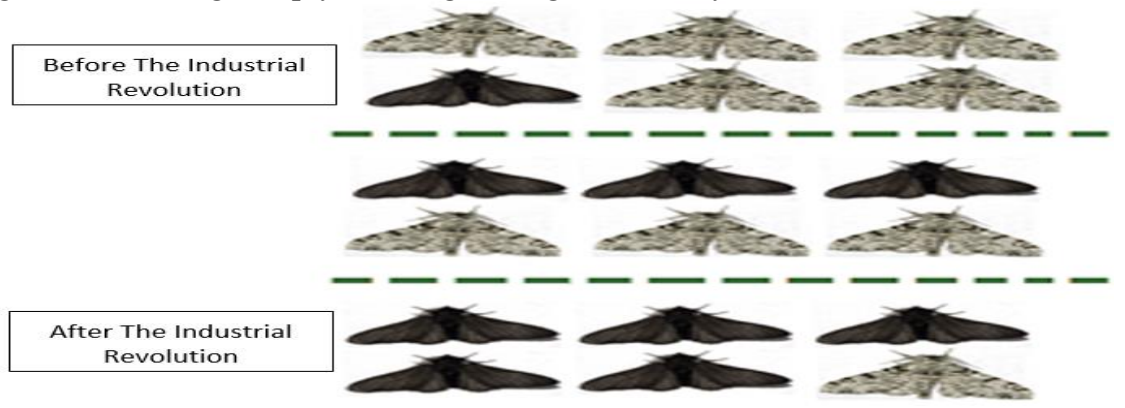

Figure 1

Changes in the Number of Moths Caused by Evolutionary Events: Before the Industrial Revolution (Above) and After the Industrial Revolution (Below).

The sample of construction of the question for Critical Thinking Disposition Tests in Biology according to the case example is:

Referring to the above case can be concluded about natural selection is ... (Maturity)

A. Only occurs in predatory populations

B. Only occurs in prey populations

C. Only occurs in the weak populations

D. Can occur in predatory populations

E. Can be influenced by other organisms

\subsection{Content validation}

Draft of the Critical Thinking Dispositions Test in Biology validated by a number of experts (validators). This step is known as content validation. Content validation which 
is involving six experts selected based on their fields, namely biology content, and assessment. The validator is asked to fill in a special form that has been provided by the researcher by checking the "YES" column for the agreed response and checking the "NO" column for the disapproving response to the draft question developed. There are two aspects assessed by the validator, namely looking at the suitability of the items on the aspects of biological material and seeing the suitability of the items with the critical disposition aspect.

\section{Trial of test (construct validation)}

After the draft of the Critical Thinking Disposition Test in Biology has been declared content valid, the following steps are the trial (construct validation). The trial referred to in this study is a construct trial (construct validation) given to 320 respondents (students of Biology Education in the Academic Year of 2017/2018). This construct trial (construct validation) aims to empirically test the quality of each item in the test, the feasibility of the test, and the adequacy in the scope of the test construct developed.

\section{Use of critical thinking disposition test in biology}

This step is intended to look at the effectiveness and practicality of the use of the Critical Thinking Disposition Test in Biology developed. This step involved 73 students of Biology Education in the Academic Year of 2018/2019. At this stage students are asked to provide responses to the Critical Thinking Disposition Test in Biology through the questionnaire provided

\section{Data Collection and Analysis}

Data collection techniques in this study were using validation format of Critical Thinking Disposition in Biology Test and questionnaire.

There are two analytical methods used in this study, namely the CVR method and the CFA method. The CVR method is used to see the quality (content validity) of test items, which is seen from the suitability of items with biological material and the suitability of items with indicators of critical thinking disposition. While the CFA method is used to see the quality of items constructively (construct validity), so that the items developed are considered to be able (valid) to measure what they want to measure. Both of these methods are used to confirm that the question items in the developed critical thinking disposition test in biology are good quality.

Content validation involved six experts in the fields. The results of content validation were analyzed using the Content Validity Ratio (CVR) method. The Content Validity Ratio (CVR) is proposed by Lawshe (1975) which is a linear transformation of the level of proportionate agreement on how many experts in the panel assess "essential" items. $\mathrm{CVR}_{\text {critical }}$ value can be used to determine how many validator (panel) members approve the item, so that it can be concluded which items must be entered or removed from the final instrument (Ayre \& Scally, 2014).

While the constructs validation results were analyzed through Confirmatory Factor Analysis (CFA) method. This factor analysis was analyzed with the help of the AMOS version 20 application. Confirmatory Factor Analysis (CFA) is a method that is applied to the assumption that the relationship between observed variables with latent variables 
is known (Byrne, 2013). Besides this factor analysis is used to examine the relationship between manifest variables (indicators) with latent variables, namely by looking at the factor loading score. According to Fornell \& Larcker's statement (1981) that in interpreting the results of the Confirmatory Factor Analysis (CFA), it can be done through three convergent validity procedures, namely Factor Loading $(>0,5)$, Composite Reliability $(>0,7)$, and Average Variance Extract $(>0,7)$. Thus, convergent validity is procedures to look at the Construct Validity of the test.

In this study item analysis is not done, because theoretically it is considered irrelevant. Other than that, in the CFA several analyzes have been carried out, including factor loading analysis. When viewed from the characteristics of the factor loading, it can be seen that the factor loading has similarities with some item analyzes such as the discrimination power and the difficulty index of the item. This is supported by the statement of Sudaryono (2012) which explains that the factor loading can be considered and used as a parameter to determine the quality of the item, both the discrimination power and the difficulty index of the item.

\section{FINDINGS AND DISCUSSION}

Minimum criteria for Content Validity Ratio (CVR) according to Wilson et al., (2012) which is a description of the concept of Lawshe (1975) for a number of different experts can be seen in Table 1 .

Table 1

Minimum Number of Experts Required to Agree Item Essential

\begin{tabular}{llll}
\hline Experts Size & CVR $_{\text {minimum }}$ Value & Experts Size & CVR $_{\text {minimum }}$ Value \\
\hline 5 & 0.73 & 13 & 0.44 \\
6 & 0.64 & 14 & 0.42 \\
7 & 0.58 & 15 & 0.41 \\
8 & 0.53 & 20 & 0.36 \\
9 & 0.52 & 25 & 0.32 \\
10 & 0.50 & 30 & 0.29 \\
11 & 0.48 & 35 & 0.27 \\
12 & 0.46 & 40 & 0.26 \\
\hline
\end{tabular}

The findings in the Content Validity Ratio (CVR) analysis explain that not all construct items in the draft of Critical Thinking Disposition Test in Biology are approved by six validators or experts. There are several items that are not approved by one expert (only approved by five validators or experts). If seen from the minimum value or the critical value of the Content Validity Ratio (CVR) for six experts, it can be concluded that all constructs of the item questions in the draft of Critical Thinking Disposition Test in Biology are still categorized as valid and usable. In addition, the results of CVR analysis on the draft of Critical Thinking Disposition Test in Biology show the value of CVR with a range of 0.67 to 1 . The value of Content Validity Ratio (CVR) 1 means that all validators or experts agree on the construct of the item being developed. While the value of 0.67 on the value of Content Validity Ratio (CVR) explains that only one expert or validator who disagrees with the construct of the item being developed (Syahfitri, 2019). 
Thus, it can be concluded that the value is greater than 0.64 (minimum CVR), so the items on the Critical Thinking Disposition Test in Biology have good content validity.

The next step is to do a construct test on the items for the seven critical thinking disposition indicators namely Truth-Seeking, Open-Mind, Analyticity, Systematicity, Self-Confidence, Inquisitiveness, and Maturity. The construct validation found the results that from the initial number of items, each critical thinking disposition indicator (22 items) was only a few items that could be said to be valid (having a factor loading value above 0.5). These results are as follows: truth-seeking 16 items of questions, open-mind of 16 items, analyticity of 18 items, systematicity of 20 items, selfconfidence of 17 items, inquisitiveness of 10 items, and maturity of 20 items.

Based on the above results it can be seen that not all indicators of critical thinking disposition have the same number of valid items. Comparison of the number of valid question items is then selected and taken as item in the final construct in the Critical Thinking Disposition Test in Biology through several considerations. The detailed comparison of the number of valid items for each indicator of critical thinking disposition can be seen in Table 2 .

Table 2

Comparisons of Valid Item Numbers for Indicators

\begin{tabular}{|c|c|c|c|c|c|c|c|c|}
\hline \multirow[t]{2}{*}{$\begin{array}{l}\text { Question } \\
\text { Cluster }\end{array}$} & \multicolumn{7}{|c|}{ Indicators of Critical Thinking Disposition } & $\begin{array}{l}\text { Item Points } \\
\text { Representing Final } \\
\text { Constructions of Test }\end{array}$ \\
\hline & $T S$ & $O M$ & $A N$ & SIS & $S C$ & $I N$ & $M A$ & \\
\hline 1 & $\sqrt{ }$ & $\checkmark$ & $\checkmark$ & $\checkmark$ & $\checkmark$ & $\checkmark$ & $\checkmark$ & $\checkmark$ \\
\hline 2 & & $\checkmark$ & $\checkmark$ & $\checkmark$ & $\checkmark$ & & $\checkmark$ & \\
\hline 3 & $\checkmark$ & $\checkmark$ & $\checkmark$ & $\checkmark$ & $\checkmark$ & $\checkmark$ & $\checkmark$ & $\checkmark$ \\
\hline 4 & & $\checkmark$ & $\checkmark$ & $\checkmark$ & $\checkmark$ & & $\checkmark$ & \\
\hline 5 & $\checkmark$ & $\checkmark$ & & $\checkmark$ & $\checkmark$ & & $\checkmark$ & \\
\hline 6 & $\checkmark$ & $\checkmark$ & $\checkmark$ & $\checkmark$ & $\checkmark$ & $\checkmark$ & $\checkmark$ & $\checkmark$ \\
\hline 7 & & $\checkmark$ & $\checkmark$ & $\checkmark$ & $\checkmark$ & & $\checkmark$ & \\
\hline 8 & $\checkmark$ & $\checkmark$ & $\checkmark$ & $\checkmark$ & $\checkmark$ & & $\checkmark$ & \\
\hline 9 & $\checkmark$ & $\checkmark$ & $\checkmark$ & $\checkmark$ & $\checkmark$ & $\checkmark$ & $\checkmark$ & $\checkmark$ \\
\hline 10 & & & & & & & & \\
\hline 11 & $\checkmark$ & $\checkmark$ & $\checkmark$ & $\checkmark$ & $\checkmark$ & $\checkmark$ & $\checkmark$ & $\checkmark$ \\
\hline 12 & $\checkmark$ & $\checkmark$ & $\checkmark$ & $\checkmark$ & $\checkmark$ & $\checkmark$ & $\checkmark$ & $\checkmark$ \\
\hline 13 & & & & $\checkmark$ & & & & \\
\hline 14 & $\checkmark$ & $\checkmark$ & $\checkmark$ & $\checkmark$ & $\checkmark$ & $\checkmark$ & $\checkmark$ & $\checkmark$ \\
\hline 15 & $\checkmark$ & $\checkmark$ & $\checkmark$ & $\checkmark$ & $\checkmark$ & $\checkmark$ & $\checkmark$ & $\checkmark$ \\
\hline 16 & & & & & & & & \\
\hline 17 & & $\checkmark$ & & & & & & \\
\hline 18 & $\checkmark$ & $\checkmark$ & $\checkmark$ & $\checkmark$ & $\checkmark$ & $\checkmark$ & $\checkmark$ & $\checkmark$ \\
\hline 19 & & $\checkmark$ & $\checkmark$ & $\checkmark$ & $\checkmark$ & & & \\
\hline 20 & $\checkmark$ & $\checkmark$ & $\checkmark$ & $\checkmark$ & $\checkmark$ & $\checkmark$ & $\checkmark$ & $\checkmark$ \\
\hline 21 & & & & & & & & \\
\hline 22 & & & & & & & & \\
\hline
\end{tabular}

Note: TS (Truth-seeking), OM (Open-mind), AN (Analyticity), SIS (Systematicity), SC (Self-confidence), IN (Inquisitiveness), and MA (Maturity).

Table 2 explains the 22 clusters of questions on Critical Thinking Disposition Tests in Biology, followed by valid items for each indicator of critical thinking disposition. 
Based on the table, it was found that the items for each indicator of critical thinking disposition that have valid similarities were only in groups of questions with numbers 1 , $3,6,9,11,12,14,15,18$, and 20 , so that only ten clusters the question is considered the final construction result of the Critical Thinking Disposition Test in Biology. The selection of ten clusters of questions was carried out with the consideration that the characteristics of each group of questions were presented in the form of a case or issue with each question consisting of seven questions of critical thinking disposition indicators. Thus, each question is expected to be able to see the seven components of critical thinking dispositions. Another consideration is that each question must represent every concept of biological material. Based on several considerations, it can be concluded that ten clusters of questions are considered to represent seven indicators of critical thinking disposition and represent four biological material.

After obtained ten clusters of questions as the final construct of a Critical Thinking Disposition Test in Biology, the next step is to make a measurement model consisting of seven measurement models of critical thinking disposition indicators that are valid or said to be feasible (joint model). Each indicator model of critical thinking disposition consists of only ten items that are valid. Then the model is analyzed through Confirmatory Factor Analysis (CFA) with the help of the AMOS application. The model generated after the Confirmatory Factor Analysis (CFA) test for the combined model between the seven critical thinking disposition indicators is presented in Figure 2.

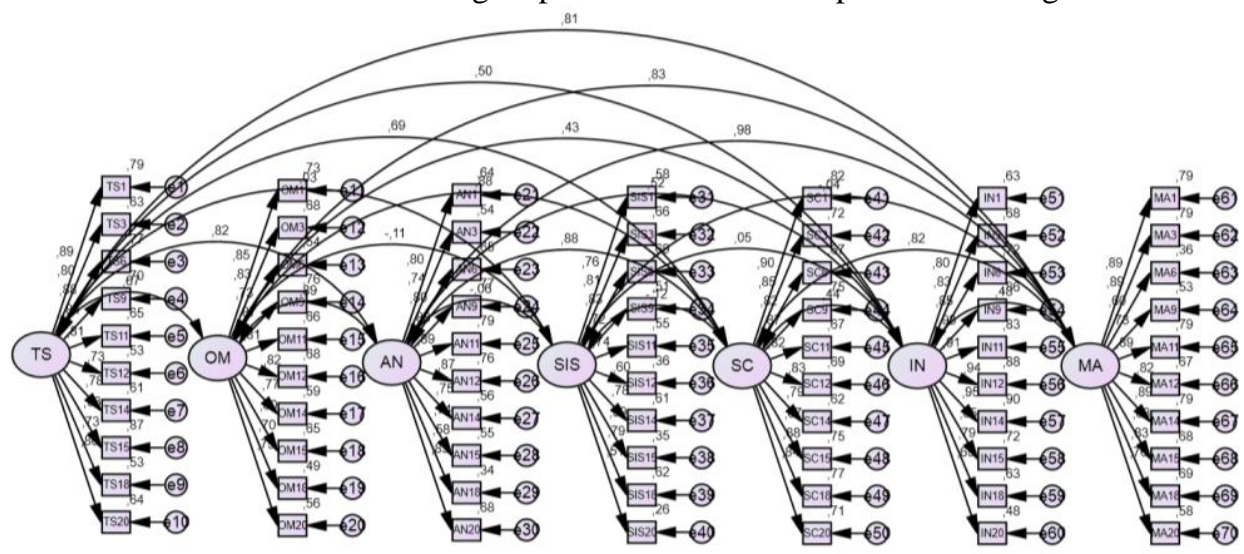

Figure 2

Model of Critical Thinking Disposition Test in Biology

In Figure 2 it can be seen based on the Confirmatory Factor Analysis (CFA) results in the Critical Thinking Disposition Tests in Biology model shows that ten question groups have an acceptable factor loading value which has a value greater than 0.5 (hair et $a l$., 2010).

In addition to the model of Critical Thinking Disposition Test in Biology, the output results from the AMOS application also display feasibility tests, factor loading, and Average Variance Extract (AVE). The feasibility test of this model is the first step in interpreting the CFA results with several criteria, Chi-square minimum discrepancy 
divided by its degrees of freedom, Goodness of Fit Indices (GFI), Adjusted Goodness of Fit Indices (AGFI), and Root Mean Squares Residual (RMSR). The model will be considered feasible if it has fulfilled one of these criteria (Widarjono, 2015). The feasibility test can be seen in Table 3 .

Table 3

Feasibility Index of Final Construction of Critical Thinking Disposition Tests in Biology

\begin{tabular}{lll}
\hline Fit Index & $\begin{array}{l}\text { Recommended Value } \\
\text { (Hair } \text { et al., 2010) }\end{array}$ & $\begin{array}{l}\text { Critical Thinking } \\
\text { Disposition Tests }\end{array}$ \\
\hline$X^{2} /$ df & $\leq 3$ & 1.899 \\
RMSEA & $\leq 0.08$ & 0.053 \\
GFI & $\geq 0.9$ & $\mathbf{0 . 7 0 3}$ \\
RMR & $<0.5$ & 0.010 \\
TLI & $\geq 0.9$ & 0.902 \\
CFI & $\geq 0.9$ & 0.906 \\
PNFI & The higher, the better & 0.790 \\
\hline
\end{tabular}

Based on Table 3, it can be seen that not all eligibility criteria meet the value of the feasibility test criteria, namely the value of the Good Fit Index (GFI) criteria. If seen from the value of the Good Fit Index (GFI) that is produced is 0.703 is a number that has approached the number one, so that the value can still be said to meet the test value of the test. In addition, the results show that the combined measurement model has more than one feasibility test. Thus, it can be concluded that the combined measurement model of the Critical Thinking Disposition Test in Biology is feasible.

Table 4 describes the factor loading value, Average Variance Extract (AVE) value, and test reliability value. Reliability testing in this study used the Composite Reliability (CR) method.

Table 4

Factor Loading and Convergent Validity

\begin{tabular}{|c|c|c|c|c|c|c|c|c|c|}
\hline \multirow[t]{2}{*}{ No } & \multirow{2}{*}{\multicolumn{2}{|c|}{$\begin{array}{l}\text { Convergent } \\
\text { validity }\end{array}$}} & \multicolumn{7}{|c|}{ Constructs } \\
\hline & & & $\begin{array}{l}\text { Truth- } \\
\text { seeking }\end{array}$ & $\begin{array}{l}\text { Open- } \\
\text { mind }\end{array}$ & Analyticity & $\begin{array}{l}\text { Systemati } \\
\text { city }\end{array}$ & $\begin{array}{l}\text { Self- } \\
\text { confident }\end{array}$ & $\begin{array}{l}\text { Inquisiti } \\
\text { veness }\end{array}$ & Maturity \\
\hline 1 & AVE & & 0.67 & 0.63 & 0.63 & 0.52 & 0.72 & 0.73 & 0.67 \\
\hline 2 & $\mathrm{CR}$ & & 0.95 & 0.94 & 0.94 & 0.91 & 0.96 & 0.96 & 0.95 \\
\hline \multirow{10}{*}{3} & \multirow{10}{*}{$\begin{array}{l}\text { Factor } \\
\text { Loading }\end{array}$} & 1 & 0.892 & 0.852 & 0.799 & 0.761 & 0.904 & 0.796 & 0.887 \\
\hline & & 2 & 0.797 & 0.828 & 0.737 & 0.809 & 0.849 & 0.827 & 0.891 \\
\hline & & 3 & 0.876 & 0.732 & 0.805 & 0.832 & 0.818 & 0.850 & 0.603 \\
\hline & & 4 & 0.839 & 0.869 & 0.878 & 0.715 & 0.865 & 0.926 & 0.729 \\
\hline & & 5 & 0.809 & 0.810 & 0.888 & 0.742 & 0.816 & 0.909 & 0.889 \\
\hline & & 6 & 0.731 & 0.824 & 0.869 & 0.602 & 0.830 & 0.937 & 0.820 \\
\hline & & 7 & 0.780 & 0.765 & 0.750 & 0.781 & 0.787 & 0.946 & 0.891 \\
\hline & & 8 & 0.933 & 0.804 & 0.742 & 0.590 & 0.865 & 0.849 & 0.825 \\
\hline & & 9 & 0.728 & 0.699 & 0.585 & 0.785 & 0.876 & 0.794 & 0.833 \\
\hline & & 10 & 0.801 & 0.747 & 0.827 & 0.514 & 0.834 & 0.691 & 0.762 \\
\hline
\end{tabular}


Table 4 explains that the Critical Thinking Disposition Tests model has the value of factor loading, Average Extract Variance (AVE) and Composite Reliability (CR) is acceptable. This is shown from the Average Extract Variance and Composite Reliability values respectively as follows: truth-seeking $(\mathrm{AVE}=0.67$ and $\mathrm{CR}=0.95)$, open-mind ( $\mathrm{AVE}=0.63$ and $\mathrm{CR}=0.94)$, analyticity $(\mathrm{AVE}=0.63$ and $\mathrm{CR}=0.94)$, systematicity $(\mathrm{AVE}=0.52$ and $\mathrm{CR}=0.91)$, self-confidence $(\mathrm{AVE}=0.72$ and $\mathrm{CR}=0.960)$, inquisitiveness $(\mathrm{AVE}=0.73$ and $\mathrm{CR}=0.96)$, and maturity $(\mathrm{AVE}=0.75$ and $\mathrm{CR}=$ 0.95). In this study the reliability test is seen with the Composite Reliability method which is another guide to seeing reliability tests (Bollen \& Long, 1993).

The valid instruments of Critical Thinking Disposition Test in Biology are considered to have the advantage of measuring instruments of critical thinking dispositions with types of inventory. Critical Thinking Disposition Test in Biology is a test instrument that is content bound, while inventory instruments are general (not content bound). Critical Thinking Disposition Test in Biology that is made contextually in biology is considered to be more objective in seeing critical thinking dispositions. In addition, Critical Thinking Disposition Test in Biology consists of questions that lead or lead someone to explore their tendencies or dispositions. These questions are accommodated by cases relating to biological content and with these types of questions make students not memorize concepts and can answer according to what they experience. This causes can minimize the occurrence of responses or answers to students who cheat. Like the statement expressed by Widhiarso (2010) which explains that there is a tendency for subjects to give deceptive responses on a psychological scale. This is in line with the statement of Marcus (2009) which states that a number of studies show that psychological measurements in the form of inventory scale are vulnerable to deceptive responses.

Practicality tests show that the quality level of the Critical Thinking Disposition Test in Biology is categorized as good, ie with the average criteria (78.9\%). This is supported by the results of the response analysis of 73 students on each item statement with a score range of 219-237 (minimum score of 73 and maximum score of 292 for each item statement), so that the response given by students to the Critical Thinking Disposition Test in Biology is on the Agree (S) scale, that is, with an average score of 3 for each item statement.

Based on the results of the analysis of student responses, it was concluded that the Critical Thinking Disposition Test in Biology has a relatively good practical value. This is indicated by the time needed by students to work on the problem, namely 150 minutes for the number of questions about ten clusters of questions. In addition, the results of the questionnaire response analysis or student responses indicate that the Critical Thinking Disposition Test in Biology can be well understood by students, scientific terms and languages used in questions are easily assertive and easy to understand. An interesting display of the Critical Thinking Disposition Test in Biology makes students able to work on the questions enthusiastically. Furthermore, the image is presented clearly and does not contain ambiguity so that it can help students understand the problem. In addition, working on the Critical Thinking Disposition Test in Biology can encourage students to think critically (Syahfitri, 2019). This is in line with the statement of Masduki and 
Poerwati (2008) that the quality of practicality means that tests are not difficult to implement in terms of financing and implementation.

\section{CONCLUSION}

Based on the results and discussion on the findings in this study it can be concluded that model of the Critical Thinking Disposition Tests in Biology developed is feasible. This is shown from the results of the CFA analysis that ten questions groups for the seven indicators of critical thinking disposition meet good instrument criteria, namely having good content validity and construct validity. In addition, the Critical Thinking Disposition Tests model has a high-reliability value. Thus, it can be concluded that Critical Thinking Disposition Tests in Biology can be used to measure students' critical thinking dispositions in biology education.

The valid of the Critical Thinking Disposition Test in Biology can be used in the learning process to see the extent to which students' critical thinking dispositions profile. In addition, the Critical Thinking Disposition Test in Biology has the potential as an instrument to measure learning outcomes, comprehensive tests, and New Student Admission Selection, especially for Biology Education majors.

The next researcher can make the development of the Critical Thinking Disposition Test in Biology as a reference in developing critical thinking disposition instruments for certain subjects or other fields. In addition, this test can be an alternative instrument for measuring one's disposition in subsequent studies, namely in the context of biology.

\section{REFERENCES}

Ayre, C., \& Scally, A. J. (2014). Critical values for Lawshe's content validity rasio: Revisiting the original methods of calculating. Measurement and Evaluation in Counseling and Development, 47, 79-86.

Bollen, K.A., \& Long, J. S. (1993). Testing stuctural equation models. Bury Park: Sage.

Byrne, B. M. (2013). Structural equation modeling with AMOS: Basic concepts, applications, and programming. New York, NY: Routledge.

Facione, P. A., Facione, N. C., \& Carol, A. G. (2000). The disposition toward critical thinking: Its character, measurement, and relationship to critical thinking skill. Informal Logic. 20, 61-84.

Facione, P. A., Giancarlo, \& Joanne, G. (1995). The disposition toward critical thinking. Journal of General Education, 44, 1-25.

Fornell, C., \& Lacker, D. F. (1981). Evaluating structural equation models with unobservable variables and measurement error. J. of Marketing Research, 18, 39-50.

Ghupta, K. I., Iranfar, S., Iranfar, K., Mehraban, B., \& Montazeri, N. (2012). Validly and reliability of California critical thinking disposition inventory (CCTDI) in Kermanshah University of medical sciences. Journal of Edu R Med S, 1, 6-10. 
Graham, K. (2012). Development and validation of a measure of intention to stay in academia for physician assistant faculty (Unpublished doctoral dissertation). University of Toledo, Ohio, USA.

Hair, J. F., Black, W. C., Balin, B. J., \& Anderson, R. E. (2010). Multivariate data analysis. New York, NY: Maxwell Macmillan International Editions.

Hamdi, S., Kartowagiran, B., \& Haryanto. (2018). Developing a testlet model for mathematics at elementary level. International Journal of Instruction, 11, 375-390.

Iskifoglu, G. (2014). Cross-cultural equivalency of the California critical thinking disposition inventory. Educational Science: Theory and Practice, 14, 159-178.

Lawshe, C.H. (1975). A quantitative approach to content validity. Personnel Psychology, 28, 563-575.

Marcus, B. (2009). 'Faking' from the applicant perspective: A theory of selfpresentation in personnel selection settings. Int. J. of Selection and Asses., 17, 417-430.

Mardapi, D. (2008). Techniques for preparing test and test instruments. Jogjakarta, Indonesia: Mitra Cendikia.

Masduki, \& Poerwati, E. (2008). Develop tests as evaluation instruments. Learning assessment. University of Muhammadiyah Malang. Malang, Indonesia: UMM Press.

Sendag, S., Erol, O., Sezgin, S., \& Dulkadir, N. (2015). Preservice teachers' critical thinking dispositions and web 2.0 competencies. Contemporary Educational Technology, 6, 172-187.

Sudaryono. (2012). The various of detecting the existence of differential item function (DIF) item national exam with classical tests theory. Educ. and Cult. J., 18, 132-144.

Syahfitri, J. (2019). Testing Validity and practicality of critical thinking disposition tests in biology. Journal of Science Education, 7, 30-35.

Widarjono, A. (2015). Applied multivariate analysis. Yogyakarta, Indonesia: UPP STIM YKPN.

Sumintono, B., \& Widhiarso, W. (2015). RASCH modeling application on educational assessment. Cimahi, Indonesia: Trim Komunikata.

Widhiarso, W. (2010). The tendency of subjects to give deceptive responses to the psychological scale. Retrieved from https://blog.ugm.ac.id/2010/06/18/centend-subjekgiving-respon-menipu-teradap-skala-psikologi/.

Widhiarso, W. (2011). Social compliance orientation and deception response in measuring tools in the context of work selection. BENEFIT Journal of Management and Business, 15, 79-90.

Wilson, F. R., Pan, W., \& Schumsky, D. A. (2012). Recalculation of the critical values for Lawshe's content validity ratio. Measurement and Evaluation in Counseling and Development, 45, 197-210.

Yuksel, G., \& Alci, B. (2012). Self-efficacy and critical thinking dispositions as predictors of success in school practicum. International Online Journal of Educations of Educatioal Sciences, 4, 81-90. 